\title{
Normatividad, asimilación y transgresión en Teoría Queer
}

\author{
Normativity, assimilation, and transgression in Queer Theory
}

Mariela Solana*

Universidad Nacional Arturo Jauretche, Florencio Varela, Buenos Aires, Argentina

\section{Resumen}

En este artículo se analiza y evalúa una crítica formulada contra la teoría queer que apareció en un número especial de la conocida revista differences en el año 2015. En ese número especial, editado por Robyn Wiegman y Elizabeth Wilson, se cuestiona el modo en que los estudios queer conciben las normas, especialmente, aquellas posiciones que defienden una idea de lo queer como una mera oposición, enfrentamiento o corrimiento de las regulaciones sexuales vigentes. Además de demostrar que la lectura de Wiegman y Wilson es problemática, este artículo explora, en primer lugar, por qué se considera a lo queer como un movimiento anti-normativo y, en segundo lugar, si existen contribuciones queer que permitan evadir la crítica recibida. A pesar de defender la importancia de no caricaturizar los estudios queer, el artículo pone en discusión un peligro latente en este tipo de teoría crítica: la fetichización de lo transgresor y la demonización de quienes no logran encarnar el ideal rupturista. El artículo argumenta a favor de una teoría queer que, al mismo tiempo que ataque radicalmente la violencia normativa, pueda reconocer y entender las seducciones de lo normativo, incluso entre quienes habitan posiciones queer.

Palabras clave: Teoría queer. Normatividad. Anti-normatividad. Política disidente. Transgresión.

"MS: Doctora, e-mail: mariela.solana@gmail.com 


\section{Abstract}

This paper explores and assess the critique of Queer Theory that appeared in a special number of the well-known Journal differences, in 2015. This special number, edited by Robyn Wiegman y Elizabeth Wilson, puts into question the ways in which Queer Theory has conceived of norms, especially, among those queer thinkers that defend an idea of queerness as a mere opposition, confrontation or evasion of current sexual regulations. Besides trying to prove that Wiegman and Wilson are wrong in their interpretation of Queer Theory, this article explores, firstly, why is queerness so often linked to antinormativity and, secondly, if there are queer contributions that can help us evade this sort of criticism. In spite of defending the importance of not making a caricature out of Queer Theory, this article discusses one of the dangers of this kind of critical approach: the re-idealization of all-things transgressive and the demonization of those lives that cannot achieve the subversive ideal. This article argues for a Queer Theory that, simultaneously, attacks normative violence and recognizes and understands the seductions of the normative, even among those who inhabit queer positions.

Keywords: Queer Theory. Normativity. Antinormativity. Dissident Politics. Transgression.

\section{Introducción}

El surgimiento de la teoría queer, a principios de los 90, se encuentra estrechamente vinculada a la crítica a la violencia que las normas de género y sexualidad ejercen en nuestras sociedades contemporáneas. Específicamente, lo que se pone en tela de jucio es el modo en que ciertos ideales, creencias y valores sobre el género y la sexualidad tienden a favorecer y naturalizar algunas identidades de género y orientaciones sexuales en detrimento de otras. El blanco crítico fundamental en esos primeros años de producción teórica es la heteronormatividad entendida como una serie de instituciones, discursos y prácticas que hacen que la heterosexualidad parezca coherente, natural, obligatoria y también privilegiada. Esta matriz heterosexual, como la denomina Judith Butler, asume y fomenta la alineación entre cuerpo, género y deseo sexual, es decir 
da por sentado que para que los cuerpos sean coherentes y tengan sentido debe haber un sexo estable expresado mediante un género estable (masculino expresa hombre, femenino expresa mujer) que se define históricamente y por oposición mediante la práctica obligatoria de la heterosexualidad (BUTLER, 2007, p. 292).

A medida que los movimientos de diversidad sexual fueron alcanzando avances legales y sociales, la teoría queer encontró un nuevo objeto de sospecha: la homonormatividad. Esta noción, que suele ser adjudicada a Lisa Duggan, apunta al modo en que ciertas personas LGBT adoptan

una política que no desafía los presupuestos e instituciones heteronormativas dominantes sino que la sostiene y defiende, al mismo tiempo que promete la posibilidad de un electorado gay desmovilizado y una cultura gay privatizada, despolitizada, basada en la domesticidad y el consumo (DUGGAN, 2002, p. 179) ${ }^{1}$.

Si bien la adquisición de nuevos derechos por parte de las minorías sexuales parecería ser, en principio, un motivo de celebración, muchos autores queer desconfían ya que, en ocasiones, esto implicó acceder a instituciones que no sólo fueron construidas sobre la base de la exclusión de dichas minorías - como el matrimonio y las fuerzas armadas - sino que son pilares de la cultura heteronormativa, patriarcal y capitalista. A pesar de que la noción de homonormatividad tiene un aire de familia con la idea de heteronormatividad, incluye aspectos diferentes. Si la heteronormatividad asume y proyecta la heterosexualidad en todos los individuos, la homonormatividad no asume y proyecta la homosexualidad en toda la población sino que suele ser empleada para nombrar aquellas prácticas, al interior de los colectivos LBGT, que incorporan y celebran los ideales de la familia monógama y reproductiva heterosexual.

En el 2015, un número especial de la conocida revista estadounidense differences: A Journal of Feminist Cultural Studies se dedicó a poner

\footnotetext{
${ }^{1}$ Todas las traducciones del inglés al español fueron realizadas por la autora de este artículo.
} 
en tela discusión esta asociación inmediata entre lo queer y la anti-normatividad. En los distintos artículos que conforman la revista se investiga y problematiza no sólo el modo en que la teoría queer concibe las normas sino también su proyecto de resistencia a las mismas. Según las editoras de este número, Robyn Wiegman y Elizabeth Wilson, el objetivo central no es sólo crítico sino también afirmativo: hacer avanzar a los estudios queer más allá de su obstinado ataque normativo: “¿Qué haría la teoría queer si su alianza con la anti-normatividad fuera menos segura?" (2015, p. 1). Lo que este número de differences nos demuestra es que, lejos de ser un tema saldado, la relación entre lo queer y lo (anti) normativo sigue mereciendo nuestra atención analítica.

En este artículo quisiera examinar el modo en que la teoría queer entiende la crítica a las normas, su concepción de la relación entre lo disidente y lo normal, así como también las propuestas políticas que se desprenden de estas ideas. Asimismo, quisiera evaluar la crítica de las editoras del número especial de differences previamente mencionado y reflexionar sobre qué significa la anti-normatividad queer. Tal como intentaré demostrar, si bien hay ciertas dificultades en cómo algunos autores queer entienden la relación entre la sexualidad y las normas, la propuesta de Wiegman y Wilson también es problemática. Finalmente, abrevaré en la teoría afectiva de Sara Ahmed para ofrecer una imagen alternativa de cómo concebir lo normativo que, sin perder el afán crítico, tome en serio las ataduras a lo normal y lo ordinario que todas las personas podemos tener. El objetivo central del artículo es argumentar que así como la teoría queer debe mantener una actitud recelosa hacia la violencia normativa, también debe desconfiar de cualquier fetichización de la transgresión.

\section{La teoría queer y lo normativo}

En esta primera sección, quisiera presentar un estado del arte que permita entender por qué se suele vincular la teoría queer a la anti-normatividad. A pesar de que lo queer suele ser asociado a formas de vida que desobedecen las normas heterosexuales, muchas veces se 
aclara que queer no es sinónimo de persona gay y/o lesbiana. Esto es así, por un lado, porque puede ser utilizado para referirse a una amplia gama de prácticas, relaciones, actos y formas de vida que rompen con la idealización del sexo heterosexual, reproductivo y en el marco del matrimonio (como el sadomasoquismo, la prostitución, las relaciones poliamorosas, las vidas trans, los cuerpos diversos, etc). Según David Halperin, lo queer apunta no a una identidad fija sino a "todo lo que está en desacuerdo con lo normal, lo legítimo, lo dominante" (2007, p. 83). Lo queer, en este sentido, remite a una posición de resistencia, distancia o tensión respecto a las normas de género y sexualidad hegemónicas en una sociedad dada. Por otro lado, el término queer no puede ser sinónimo de gay y lesbiana porque, en ocasiones, se utiliza para diferenciarse de prácticas gays que parecen no alejarse radicalmente de los ideales heterosexuales. Como afirma Elizabeth Grosz,

una de las razones conocidas por las que muchos han adoptado el término 'queer' fue para posicionarse fuera tanto de la comunidad heterosexual como de la comunidad gay que, muchas personas afirman, funciona de forma igualmente coercitiva y moralista (GROSZ, 1995, p. 216).

Si lo queer no es algo fijo ni determinado a priori sino una cuestión de grado, de un mayor o menor cumplimiento de las normas dominantes, es factible pensar que hay aspectos de la vida de una persona que lo vuelven queer y otras que no, así como también que ciertos actos puedan ser considerados queer en un contexto y no en otro (por ejemplo, un varón gay casado puede no cumplir con los mandatos de la heterosexualidad compulsiva pero sí acercarse al ideal de una vida amorosa enmarcada en el matrimonio). En este sentido, creo que las palabras de William Turner son iluminadoras porque apuntan al estatus relacional, voluble y oposicional del término queer en lugar de reducirlo a un contenido positivo: "Para algunos, soy queer porque soy gay. Para otros, soy queer por la forma en que me comporto como gay. Para mí, soy queer por la relación de amor/odio que tengo con la categoría 'gay'”' (2000, p. 9). 
Si lo queer es un adjetivo que califica actos, relaciones o modos de ser que no se ajustan a los parámetros de lo sexualmente "normal", esto no significa necesariamente que la meta sea que estos actos, relaciones o modos de ser sean admitidos como "normales". Por el contrario, para toda una serie de escritores queer el punto es reivindicar lo anormal, lo torcido, lo extraño y no caer presas de las seducciones normativas. En The Trouble with Normal (1999) de Michael Warner - un libre clave en la primera década de producción queer - este argumento aparece claramente. Como su título lo indica, lo normal, lejos de ser una aspiración, puede ser un problema, especialmente para aquellos que fueron tradicionalmente considerados anormales. Allí, el autor cuestiona la posición de algunas personas y colectivos gays - como la revista Hero, de 1998, o el libro Virtually Normal, de 1995, escrito por Andrew Sullivan - que buscan defender sus derechos proclamando que ellos son tan normales como el resto del mundo. Como nota Warner, la estrategia de estos grupos para ganar respeto, borrar el estigma y presentarse como ciudadanos respetables consiste en "purificar el grupo" (1999, p. 42), básicamente ocultando aquello que la sociedad ve como más problemático y aberrante: el sexo gay. El autor remarca que, paradójicamente, se trata de una estrategia política antipolítica: "el punto de ser normal es mezclarse, no tener ninguna diferencia visible y ningún conflicto" (1999, p. 60). El problema es que, a medida que algunas personas gays - usualmente, varones, blancos, clase media y en relaciones estables y monogámicas - adquieren respeto y decencia, otros sujetos queer son construidos como resabios patológicos. Frente al repudio al estigma presente en aquellos grupos gays que defienden su "normalidad", el autor celebra la estigmofilia, es decir, armar espacios queer donde se pueda "aprender a valorar aquello mismo que el resto del mundo desprecia" (1999, p. 42). Lo queer, así, aparece como una tercera alternativa, una forma de decir "no somos patológico pero no creas que por eso queremos ser normales" (1999, p. 59).

La reivindicación de un estilo de vida alejado de lo considerado normal aparece también en lo que se conoce como tesis anti-sociales en teoría queer. El pensador más comúnmente asociado a estas tesis es Leo Bersani, especialmente, por su libro Homos (1995). Allí el autor desarrolla 
la idea de que la potencia política de la homosexualidad no debe apagarse por medio de la normalización sino justamente afianzarse en su oposicionalidad. Otro autor importante asociado a las tesis anti-sociales es Lee Edelman. En No Future (2004), Edelman define a lo queer en oposición a lo que él denomina futurismo reproductivo. La noción de futurismo reproductivo remite, por un lado, al valor que se le adjudica a la reproducción para garantizar el futuro y, por otro lado, al carácter repetitivo de lo social, es decir, a la imposibilidad de imaginar una acción política que aspire a alcanzar un futuro radicalmente diferente al presente. Este agotamiento de la imaginación política se hace patente, por ejemplo, en la lucha de personas LGBT por ingresar a la institución matrimonial y tener hijos, algo que, según esta perspectiva, en lugar de desarmar el tejido social, lo reafirma y fortifica. Frente a esto, el autor caracteriza a lo queer como una negatividad cuya valor ético yace en "aceptar su estatus figural como resistencia a la viabilidad de lo social" (2004, p. 3). Si bien las personas queer no están destinadas a asumir su negatividad, y esto es algo que Edelman reconoce, esto no significa que no deban hacerlo. De hecho, es allí donde el autor reconoce su valor ético: "Nosotros, los sinthomosexuales ${ }^{2}$ que figuramos la pulsión de muerte de lo social, debemos aceptar que seremos denigrados como agentes de esa amenaza" (2004, p. 153). En lugar de embarcarse en proyectos reproductivos, el punto es abrazar la fuerza negativa de lo queer. Sorprendentemente, quien logra reconocer más cabalmente la potencia negativa de lo queer no es la izquierda sino la derecha. El miedo conservador a que los homosexuales rompan el tejido social, lejos de ser un error, es el máximo reconocimiento del potencial crítico queer. En lugar de negar esta acusación "en lugar de intentar convencer a la derecha de que las personas gays, lesbianas y trans son tan "normales" como ellos - Edelman llama a que quienes habitan posiciones queer proclamen: "Al carajo con el orden social y con el Niño en cuyo nombre nos vemos aterrorizados colectivamente" (2004, p. 29).

2 Sinthomosexual es otra de las figuras que utiliza Edelman para nombrar la fuerza queer que se tensiona el orden reproductivo. En inglés, el prefijo "sin" apunta a la constitución de la homosexualidad como un pecado aunque también juega con la similitud de la palabra acuñada y el término psicoanalítico "síntoma". 


\section{¿Una teoría queer sin anti-normatividad?}

Como vimos en los apartados anteriores, la teoría queer sospecha no sólo del modo en que la heteronormatividad ejerce violencia sobre las vidas no heterosexuales sino también de aquellas estrategias políticas de grupos LGBT que, en lugar de asumir su carácter oposicional, intentan ya sea afirmar su propia "normalidad", ya sea incorporarse a instituciones que solían rechazarlos, como el matrimonio y el ejército. En el 2015, un número especial de la revista differences se dedicó a analizar justamente esta relación aparentemente intrínseca entre lo queer y la anti-normatividad. Por anti-normatividad, las editoras entienden el llamado a oponerse a toda una serie de creencias e instituciones: la heteronormatividad, la homonormatividad, la idealización de la blancura, los valores familiares, el casamiento, la monogamía, el cristianismo, etc. Para Annamarie Jagose, quien participa de la convocatoria, existe una sinonimia entre lo queer y lo anti-normativo que "se hace evidente en sus impulsos anti-asimilacionistas, anti-comunitaristas o anti-sociales, anti-identitarios, anti-separatistas y anti-teleológicos" (2015, p. 27). El problema de este impulso anti-normativo es que, al defender la resistencia y la marginalidad, termina ofreciendo un análisis insuficiente y pobre de la normatividad misma. El objetivo principar de las editoras, Wiegman y Wilson, no es abandonar la teoría queer sino que ésta pueda dar cuenta, con mayor sofisticación conceptual, de la naturaleza compleja de las normas: "las normas son más dinámicas y políticamente interesantes que lo que la crítica queer usualmente admite" (2015, p. 2). Para ellas, en muchos de los textos fundacionales de los estudios queer, encontramos una mirada demasiado dicotómica de la relación entre las normas y la resistencia, entre lo hegemónico y lo queer: existen las normas que oprimen y una serie de desobedientes que se oponen a ellas. El problema de esta dicotomía es doble. Por un lado, no logra reconocer que las subculturas sexuales no sólo están atravesadas por normas propias (que también ejercen violencia) sino que, incluso, están fuertemente influenciadas por las normas hegemónicas. No hay dos 
mundos paralelos: el de los normales y el de los abyectos - todos cohabitamos en la misma matriz normativa.

Por otro lado, la teoría queer no logra entrever que la transformación política no implica ir en contra de las normas sino "el gesto más íntimo y complicado de moverse a través [athwart]" de ellas (2015, p. 11). Así, y a pesar de que lo queer tiene, en inglés, vínculos etimológicos con la idea de retorcer o atravesar, el problema es que se lo suele utilizar como una forma de enfrentamiento o reprimenda. Retomando las advertencias de Foucault - en las primeras páginas del volumen uno de Historia de la sexualidad (2006) - las autoras se preguntan si la teoría queer no puede ser considerada un nuevo exponente de la hipótesis represiva que sólo tiene ojos para ver cómo el poder oprime a la sexualidad. Adoptar esa posición beneficia a la teoría queer ya que conduce a "que la crítica queer aparezca como el agente decisivo de la acción política" (2015, p. 11). Recordemos que el punto de Foucault era mostrar no sólo el error de quienes afirman que la sexualidad es meramente reprimida por el poder sino también que quienes anuncian esto sacan un rédito de esa afirmación: adquieren un aire de transgresión al ser capaces no sólo de ver las restricciones del poder sino de actuar en su contra. Según las editoras, los pensadores queer reproducen este gesto de denuncia y se presentan no sólo como quienes pueden posicionarse por fuera del poder para ver lo que las personas reprimidas no logran ver sino también como quienes tienen la capacidad de desmantelar la represión sexual y crear un mundo más queer.

Según las editoras, la gran dificultad de los escritos queer es que caracterizan a las normas, incorrectamente, como siendo restrictivas y excluyentes: “Cuestionamos el sentido común político que sostiene que las normas excluyen, o que algunas de nosotras estamos más cercanas a sus operaciones que otras o que la 'normatividad' es sinónimo de lo que es restrictivo o controlador o tiránico" (2015, p. 12). Ellas consideran que los teóricos queer asumen que las normas siempre están del lado de las personas privilegiadas, que afectan más a unas que a otras y que deberían ser evitadas o resistidas a toda costa. Wiegman y Wilson encuentran una estrategia para desnaturalizar esta visión errónea de lo normativo recurriendo a la historiografía de las normas. Volviendo a 
los orígenes etimológicos de la palabra "norma" -que en latín remite a la regla $\mathrm{T}$ usada por los carpinteros- las autoras recuerdan que, originalmente, este concepto hacía referencia a una regla o, mejor dicho, a la regla, es decir, a la escala de medición universal. Sin embargo, en el siglo XIX, ocurre un giro semántico: la norma ya no se vincula con la rectitud objetiva sino con el promedio social. Así, las normas dejaron de ser pensadas como un estándar universal y comenzaron a ser concebidas como una medición que, si bien es general, es relacional respecto a todos los miembros de un conjunto. De esta manera, ser comparado con la norma no es ser comparado con una singularidad objetiva sino con un promedio social, dinámico que se modifica en virtud de las transformaciones de la población. Las autoras dan un ejemplo para entender el carácter dinámico y relacional de las normas en tanto promedio social: el cambio reciente en la cantidad de géneros que admite Facebook (recordemos que pasó de reconocer dos a admitir más de cincuenta). Esta transformación "no es un desafío a la norma; es simplemente una arruga más en la tela de la normatividad de género" (WIEGMAN; WILSON, 2015, p. 16). Así, la norma no es un todo monolítico al que se le opone lo no-normativo sino que ella misma genera las condiciones de su diferenciación, de su proliferación interna. Jugando con las palabras, las autoras sostiene que si queremos llamar al sistema de normas heteronormatividad, hay que hacerlo teniendo en cuenta que lo "hetero" del sistema no es la imposición de una regla dual (varón y mujer, normal, anormal, hetero y homo) sino su carácter heterogéneo. Al bifurcar el mundo en centro y periferia, al considerar que lo queer se opone a las normas mientras lo hetero las avala, "la anti-normatividad pierde lo más interesante de la norma: que al ordenar el mundo, recoge todo." (WIEGMAN y WILSON, 2015, p. 17). Con Foucault, las autoras proponen que no hay un afuera de las normas, no hay un espacio de oposición, no hay una resistencia que logre romper el sistema normativo y esto, a su entender, es lo que los estudios queer no terminan de entender al celebrar una política anti-normativa. 


\section{Una revisión de la crítica de Wiegman y Wilson}

Considero que hay dos problemas en la crítica de Wiegman y Wilson. En primer lugar, si bien creo que es importante historizar qué se entiende por "normas" - así como también mostrar su carácter holístico y no excluyente - me pregunto si la forma en que ellas lo hacen no implica también una reducción. Entiendo que las normas afecten, condicionen y moldeen la vida de todos los individuos $-\mathrm{y}$ no sólo la de quienes se ven beneficiados por ellas - pero al enfatizar su universalidad, ¿no se pierden de vista las jerarquías de poder que se producen dentro del sistema normativo? Es cierto que el sistema heteronormativo es heterogéneo, como las autoras conceden, ¿pero no es cierto también que supone y fomenta la heterosexualidad obligatoria al mismo tiempo que posterga y violenta otras formas de sexualidad? Para pensar sobre esto podemos recurrir, tal como hacen las editoras, nuevamente a la historia. La medievalista Amy Hollywood (2001) nos recuerda que nuestro sentido moderno de norma colapsa dos ideas diferentes: el promedio -tal como afirman Wiegman y Wilson- y el imperativo. Es decir, la estadística y la eugenesia. Hollywood recuerda que, a partir del siglo XIX, las ideas de norma, normal, normalidad y normatividad estuvieron influenciadas no sólo por el análisis estadístico de la población sino también por el interés de buscar sus aplicaciones sociales. A diferencia de cómo se concebía a lo ideal en la pre-modernidad - como algo imposible de alcanzar - a partir del siglo XIX, el ideal se convirtió en el promedio. Esta imbricación entre el promedio y lo ideal hizo que se estableciera una curva estadística en la que los extremos fueron considerados desviaciones. Esto, no obstante, no siempre significó que la carga valorativa de los extremos sea necesariamente negativa ni que ambos extremos sean igualmente juzgados (pensemos en el ejemplo de la inteligencia promedio y sus extremos: se celebra la genialidad y se reprueba la idiotez). Retomando el clásico Enforcing Normalcy, de Lennard Davis, la autora señala que 
el nuevo ideal de orden jerárquico está potenciado por el imperativo de la norma, y luego es complementado por la noción de progreso, perfectibilidad humana y la eliminación de las desviaciones, para crear una visión dominante, hegemónica de lo que el cuerpo humano debería ser" (citado en HOLLYWOOD, 2001, p. 175).

Si consideramos esta relación intrínseca entre la norma como promedio y la norma como imperativo, creo que la posición crítica queer tiene más sentido. Claramente, el mundo no está dividido entre personas afectadas por las normas hegemónicas y personas que habitan en un reino queer de libertades y autonomías. Ni las acciones sociales son fácilmente demarcables entre "transgresoras" y "asimilatorias" (y volveré sobre este punto en breve). Pero que no haya un afuera de las normas, que incluso las subculturas sexuales tengas normas que muchas veces emulen las normas hegemónicas, no significa que no haya una jerarquización social que privilegie a quienes se acercan al promedio sexual y que discrimine a quienes se alejan. Es esto, a mi entender, lo que está en juego en la crítica queer a las normas y no una reivindicación de un "afuera" o de una "liberación" de toda regulación.

Ahora bien, una segunda pregunta que nos podemos hacer sobre la crítica formulada por Wiegman y Wilson es si efectivamente se aplica a los estudios queer. ¿Los estudios queer suponen una concepción negativa y restrictiva de la normatividad? Quien ha respondido con mayor vehemencia a las acusaciones de las editoras del número especial de differences ha sido Jack Halberstam. En la entrada del doce de septiembre de Bully Bloggers, "Straight Eye For the queer Theorist - A Review of "queer Theory Without Antinormativity"', Halberstam sostiene que la mayoría de las autoras de la revista, y en especial sus editoras, caen en la falacia del hombre de paja, es decir, arman un enemigo caricariturizado de la anti-normatividad queer que resulta fácil de atacar. El modo en que Wiegman y Wilson atacan a los estudios queer se basa en un análisis de dos o tres citas de obras complejas de Butler, Ahmed, Sedgwick, Halberstam, Berlant y Edelman. Sería difícil unificar a todos estas autoras bajo una única teoría de las normas, la "antinormatividad" queer, ya que 
no tienen un objeto singular, no comparten el mismo fin, siguen metodologías múltiples y ninguna de ellas abraza una posición singular, crítica a partir de la cual injustamente sacan energías y proponen cambiar el mundo" (HALBERSTAM, 2015, en línea).

Sólo para pensar en uno de esos casos, recordemos el modo en que Judith Butler caracteriza a la subversión política en El género en disputa, a saber como una repetición con diferencia. En este libro, y en toda su obra, se busca ofrecer una lectura de la acción política que no se base en un afuera, en algo previo o por debajo de las estrategias culturales existentes, sino que utilice los recursos existentes de la matriz normativa pero para combatir su costado más violento:

Si las normas que gobiernan la significación no sólo limitan, sino que también posibilitan la afirmación de campos diferentes de inteligibilidad cultural, es decir, nuevas alternativas para el género que refutan los códigos rígidos de binarismos jerárquicos, entonces sólo puede ser posible una subversión de la identidad en el seno de la práctica de significación repetitiva (BUTLER, 2007, p. 192).

En esta cita, la subversión no puede ser identificada con quienes se posicionan en un "afuera" sino que se asemeja a la estrategia de moverse a través de las normas que Wiegman y Wilson celebraban. La acción política transformadora, en la teoría butleriana, implica una negociación ardua y constante entre el uso de recursos ya existentes y el deseo de resignificar, torcer y cambiar aquello heredado.

Volviendo a Halberstam, el pensador nota que a pesar de preguntarse cómo sería una teoría queer anti-anti-normativa, las editoras jamás responden esta pregunta. Halberstam, sin embargo, sí tiene una respuesta para ofrecerles: sería "un pensamiento disciplinar, neoliberal, sin riesgos y heterosexual, igracias!" (2015, en línea). Si bien creo que, en esta última línea, Halberstam vuelve a caer en una estrategia dualista (lo queer como no liberal, no disciplinar, etc.), coincido en la necesidad de problematizar no sólo las normas, como proponen Wiegman y Wilson, sino también las fórmulas generales que se arman sobre la teoría queer. 
Ahora bien, creo que el hartazgo que aparece en la pluma de las editoras del número especial de differences algo nos dicen sobre la recepción de la teoría queer, es decir, sobre cómo la teoría queer es a menudo imaginada: como una postura radical que sólo celebra la ruptura y que demoniza el deseo por "encajar". Wiegman y Wilson advierten que uno de los peligros de esta postura es que se canonice la anti-normatividad y adquiera, irónicamente, el estatus de una nueva norma, la norma a seguir para quienes quieren ser queer. Así como sabemos que "lo normal" ha devenido "lo ideal", ¿puede lo "anormal" volverse, también, un ideal a seguir? ¿Hay formas más adecuadas, correctas, celebradas de ser anti-normativo? ¿Hay formas más adecuadas, correctas, celebradas de ser queer? ¿Puede la crítica queer a la hetero y a la homonormatividad devenir en una queer-normatividad? ¿Y qué sucede con las personas no heterosexuales -por ejemplo, un varón gay que se quiere casar, una mujer trans que quiere bautizar a sus hijos- que no logran alcanzar este ideal? Si bien comparto con Halberstam el interés por des-caricariturizar los estudios queer, temo que hay algo que sucede entre la producción, la circulación y la recepción de las ideas queer que nos deja la impresión de que lo queer es una celebración a ultranza de la abyección que vuelve a marginalizar a quienes tienen deseos por vidas ordinarias. Según Warner (2012), por ejemplo, la teoría queer ha conducido, a menudo y problemáticamente, a la competencia por establecer quién es la persona más queer. Para Sara Ahmed, por su parte, lo queer, que apareció como un término para reivindicar las vidas que no estaban cómodas siguiendo los guiones heteronormativos, también puede devenir una fuente de incomodidad: "Por momentos, me siento incómoda habitando la palabra 'queer', preocupada de que no soy lo suficientemente queer, o que no lo he sido durante demasiado tiempo o que no soy la clase correcta de persona queer" (2004, p. 151). Mi objetivo no es seguir abonando esta caracterización de lo queer sino problematizarla, mostrando que hay elementos en este campo teórico que permiten, por un lado, cuestionar la fetichización rupturista y, por el otro, repensar nuestra relación con las normas más allá de la dicotomía asimilación/transgresión. A continuación, recurriré a la teoría afectiva de Ahmed, y a una serie de advertencias críticas de Jay Prosser y Lohana 
Berkins, como fuente de inspiración para propiciar una lectura alternativa de los estudios queer y su vínculo con lo (anti)normativo.

\section{Otra forma de pensar lo normativo}

En este apartado quisiera pensar junto a las autoras queer para ver qué insumos nos ofrecen para salir de este juego de oposición entre lo normativo y lo disidente. Al igual que Wiegman y Wilson, me interesa detenerme en los problemas que se siguen de pensar la política en términos maniqueos de asimilación o ruptura pero, a diferencia de ellas, mi estrategia es bucear en las aguas queer para buscar alguna alternativa. Creo que un buen punto de arranque lo encontramos en el análisis de los afectos involucrados en la naturalización de normas que Sara Ahmed ofrece en The Cultural Politics of Emotion (2004). Allí, la autora establece una analogía entre la normatividad y la comodidad que podemos sentir al sentarnos en un sillón. Ahmed señala que si bien solemos transferir cualidades al sillón mismo (i.e. decimos que es cómodo o incómodo), la comodidad no depende del receptáculo sino del encuentro entre los dos cuerpos: el sillón y quien se sienta. Cuando nuestro cuerpo encaja bien y se siente cómodo, cuando sentimos que nos hundimos en él, nos expandimos en el espacio y perdemos conciencia de dónde nuestro cuerpo termina y el mundo comienza. El sillón, a su vez, también se va adaptando a nuestras formas lo cual contribuye a que desaparezca como objeto de consciencia. Recién cuando sentimos dolor o incomodidad volvemos la atención al cuerpo y al objeto que parece causarlo. Según la autora, es posible pensar la normatividad como una suerte de sillón que resulta cómodo para algunos cuerpos y no para otros. Ahmed sostiene que la heteronormatividad puede ser entendida como una "comodidad pública, permitiendo que algunos cuerpos se expandan hacia lugares que ya adoptaron su forma" (2004, p. 148). Siguiendo la analogía, esto tiene como resultado que, a quienes el sillón favorece, pueden olvidar que éste existe, mientras que el dolor y la incomodidad hacen que el sillón se patentice para otros sujetos. Las vidas queer son aquellas que sienten cierta incomodidad en el sillón 
heteronormativo. Esta forma de concebir la normatividad no reproduce la visión restrictiva que Wiegman y Wilson decían encontrar en los estudios queer. El sillón heteronormativo acoge a todos los sujetos pero algunos tienen el privilegio de hundirse hasta olvidar su existencia, mientras otros sufren más fuertemente sus puntas filosas.

Un segundo punto interesante de la analogía propuesta por Ahmed es que el hecho de que los cuerpos queer sientan incomodidad en espacios heterosexuales no significa que se sientan cómodos en espacios queer. Ella misma afirma, como vimos en el apartado anterior, haberse sentido incómoda habitando el término queer, sintiendo que nunca era lo suficientemente queer. Ahmed se molesta con aquellas perspectivas que demandan a los sujetos postergados abandonar las zonas de comodidad para asumir una posición de resistencia a las normas. Lo que ella se pregunta es qué tipo de sujeto supone este tipo de demanda. Ahmed desconfía, por ejemplo, del pedido que se le hace a algunas madres lesbianas de poner en cuestión, en sus barrios o comunidades, el guión heteronormativo basado en la familia y el matrimonio. La autora considera que el hecho de que algunas parejas de madres lesbianas afirmen que sus familias son iguales a cualquier otra familia, no puede ser leído como una mera asimilación ni como un fracaso político sino como una de las estrategias encontradas por estas mujeres para poder sobrevivir. Distanciándose de las posturas radicales de Warner y Edelman que expuse previamente, Ahmed considera que muchas veces esa radicalidad es imposible: "Mantener una posición activa de 'transgresión' no sólo toma tiempo sino que puede no ser posible física, social o materialmente para algunos individuos y grupos dado sus historias y sus compromisos en desarrollo" (2004, p. 153). Sin embargo, al mismo tiempo que la autora señala que algunas madres lesbianas no pueden darse el lujo de atacar, en sus barrios y comunidades, a la institución familiar clásica, ella reconoce que para otras madres lesbianas lo imposible puede ser no atacar dicha institución y presentarse como una familia igual que cualquier otra.

Lo que quisiera rescatar de la propuesta de Ahmed es que si bien aproximarse al ideal de las normas heterosexuales puede ponernos en una posición privilegiada, eso no quita que encarnar la posición 
transgresora no requiera también cierto grado de privilegio. Para muchas personas cargar la antorcha antinormativa puede ir en contra de su propia supervivencia, mientras que para otras, no hay forma de sobrevivir si no es repudiando las normas hegemónicas. Creo que la teoría queer debería leer la vulnerabilidad de algunos cuerpos no como un fracaso ni como una concesión sino como uno de los modos posibles de existir en el mundo hostil en el que vivimos. La analogía del sillón que propone Ahmed tiene un corolario fundamental y es que demuestra que no todos los cuerpos ocupan los espacios de la misma forma. No podemos armar un ranking universal de subversión o conformidad donde poder colocar a todos los sujetos, como si tuviéramos aquella regla T objetiva que mencionamos antes. Si los estudios queer están verdaderamente comprometidos con la reivindicación de una amplia gama de diversidades corporales, debería poder entender que no todos los cuerpos tienen las mismas fuerzas para llevar a cabo los mismos actos de repudio normativo. Creo que las advertencias de Ahmed permiten dudar de la celebración a ultranza de todo aquello que sea transgresor. Si, como Warner afirmaba, el peligro latente en el deseo de personas LGBT de querer ser consideradas "normales" es que lo hacen a costas de patologizar aquellas vidas que no se ajustan a los parámetros sociales, existe otra amenaza que surge de la romantización de la ruptura: la denigración de quienes no pueden, o no quieren, encarnar esa ruptura. Para Prosser (1998), éste es el gran talón de Aquiles de los estudios queer: se celebra todo lo transgresor y se demoniza aquellas formas de vida - como la de las personas transexuales que en lugar de romper las categorías binarias demandan ser consideradas varones o mujeres - que no ponen en tela de juicio los ideales normativos. Siguiendo esta misma línea crítica, podemos recordar las advertencias de la pensadora y activista travesti argentina, Lohana Berkins, sobre la demanda que se deposita sobre las personas trans a la hora de adoptar posiciones de subversión. Me interesa recuperar en particular sus reflexiones sobre cómo se trató a Florencia de la V - una travesti argentina famosa del mundo de la farándula - tras haber decidido bautizar a sus hijos. La noticia del bautismo cobró relevancia porque fue tapa de la revista Gente, una de las más populares del país. En la tapa se la veía a ella, con su marido, sus mellizos y un cura, en una iglesia. En 
la parte inferior, se leía su testimonio: "Quiero que mis hijos crezcan en la fe". Obviamente, esta tapa generó un gran revuelo y ofendió no sólo a personas católicas conservadoras sino también a gran parte de la comunidad LGBT argentina. En el artículo "Para nosotras, tolerancia cero", publicado en el suplemento "Soy" del diario Página/12 en septiembre de 2012, Berkins interviene en este debate sin reivindicar la decisión de Flor de la V - "A mí, sinceramente, lo que hizo Florencia me parece una reverenda pelotudez" (BERKINS, 2012, en línea) - pero sacando a la luz cierta hipocresía de quienes cuestionan su decisión. Berkins se molesta con quienes esperan que por el mero hecho de ser travesti, Flor de la V tenga que adoptar una política anti-normativa: “¿y qué esperaban? ¿Una declaración tipo Rosa Luxemburgo? Esperen sentadxs." (2012, en línea). Si bien Berkins reconoce que Flor de la V pudo bautizar a sus hijos porque es parte del establishment y porque posee cierto grado de privilegio, su enemigo en ese texto no es Flor de la V ni el establishment sino quienes demandan que los sujetos postergados, por el sólo hecho de serlo, encarnen posturas radicales: "Ella realizó su fantasía (una fantasía que para mí es una pavada), pero es su fantasía al fin. A nosotras siempre se nos acusa, se ponen siempre bajo la lupa nuestras actitudes. Es un poco la historia de siempre: para nosotras, tolerancia cero" (2012, en línea). Creo que las reflexiones de Berkins añaden una nueva arista del problema. No se trata, meramente, de que se celebra la transgresión y se demoniza lo reinscriptivo, como sostenía Prosser. Berkins pone el foco sobre algo más: que la demanda de torcer lo normativo suele ser dirigida hacia aquellos sujetos que sufren con más fuerza la violencia normativa, como si ellos fueran quienes deben luchar por el resto. Hay que estar atentos a cómo y a quiénes se les demanda asumir esas posiciones y recordar, como hacía Halberstam, que "la experiencia de la transgresión misma suele estar repleta de miedos, peligros y vergüenza más que de autosatisfacción heroica" (1998, p. 59). 


\section{Cierre}

En este artículo recuperé la obra de una serie de pensadoras queer con el fin poner en duda dos ideas supuestamente intrínsecas a la teoría queer: la fetichización de la transgresión y el maniqueísmo entre asimilación y transgresión. A diferencia de lo que plantean Wiegman y Wilson, creo que existen elementos en la literatura queer que permiten pensar a las normas de forma compleja y dinámica. Este artículo recurrió a la teoría afectiva de Ahmed y a la noción de subversión en Butler para demostrar que ese muñeco de paja que Wiegman y Wilson construyen se desarma cuando analizamos autores y obras específicas. Si bien coincido con las editoras en que es ingenuo dividir el mundo entre los sujetos afectados por las normas hegemónicas y quienesestán libres de su alcance opresor, encontré en la literatura queer salidas posibles a esta dicotomía. La idea de sillón en Ahmed y de matriz en Butler permiten pensar en un universo normativo que afecta y condiciona a todas las vidas pero mientras algunas acciones, prácticas y estilos corporales son bendecidos por las normas, en otros cae con más fuerza el peso de su violencia. Las teorías aquí reseñadas permiten tener una concepción de las normas dinámica y mutable, lejos del estatismo advertido por Wiegman y Wilson. Una ventaja adicional de estas aproximaciones es que nos permiten problematizar la idea de que desear algo así como el matrimonio igualitario implica una "mera asimilación". Si pensamos a la normatividad como un sillón que se modifica en virtud de los cuerpos que acoge, el hecho de que sujetos que antes se sentían incómodos ahora puedan estar un poco más a gusto - por ejemplo, teniendo el derecho a casarse - tiene como corolario que el sillón mismo se verá modificado. Así, es posible considerar que una acción que repite ideales propios de una institución pero con una diferencia no es un acto que meramente se asimila a la institución tal como existía - esa institución ya no es lo que era antes de su ingreso, se vio transformada, es algo nuevo. Tampoco es necesario posicionarse desde un afuera de las normas vigentes, como si eso fuera posible, para ejercer un cambio en la valoración, contenido y significado de las normas. Si bien es útil analíticamente seguir distinguiendo entre actos que naturalizan ideales 
sociales y actos que los ponen en tela de juicio, creo que es necesario abandonar formas maniqueas de pensar la asimilación y la transgresión. La asimilación nunca implica una adaptación a un sistema estanco que meramente suma nuevos miembros. La transgresión utiliza recursos existentes para poder realizarse, si bien algunas actos parecen acarrear cambios mínimos y otros impulsan la imaginación política hacia rumbos antes inimaginados.

Lo queer, tal como fue definido en este artículo, tiene resonancias con lo que se expresa en la siguiente frase de Grosz, "Es una cuestión de grado más o menos, más que de tipo, una cuestión de varias investiduras que todas las personas tenemos, de alguna forma $u$ otra, hacia ciertos tipos de complicidades con la estabilidad y el imperativo social" (1995, p. 216). Si, como vimos previamente, lo queer no remite tanto a una identidad sino a una posición de distancia e incomodidad respecto a las normas hegemónicas, es posible considerar que todas las personas puedan habitar y abandonar posiciones queer en distintos tiempos y espacios de sus vidas. Comparto con Grosz que puede haber posiciones queer en personas heterosexuales que mantienen relaciones sexuales por fuera del marco penetrativo y coitocentrado, así como pueden existir personas gays que deseen adoptar formas de vida muy parecidas a las de una pareja heterosexual, clase media: "simplemente ser heterosexual o ser queer, en sí mismo, no garantiza la posición de una como sexualmente radical" (GROSZ, 1995, p. 217).

El hecho de haber recuperado concepciones queer de las normas, no significa que la teoría queer esté exenta de dificultades. Como vimos, el peligro siempre latente en este tipo de aproximaciones es convertir la transgresión en un nuevo ideal a seguir que termine vulnerando y denigrando a quienes no logran encarnar el espíritu contestatario, tal como la vanguardia lo requiere. La estrategia aquí utilizada apunta a mostrar que lejos de ser un todo monolítico, la teoría queer está atravesada por nociones y posiciones divergentes, a veces contradictorias, muchas de ellas cuestionables y otras todavía fértiles. Recordemos la diferencia entre la celebración de la posición negativa queer, en el caso de Edelman y Warner, versus la lectura más comprensiva de las complicidades inevitables con lo normativo que vimos con Ahmed y Grosz. 
Ninguna fórmula general - tal como la "anti-normatividad queer" permite identificar y valorar estas disonancias internas.

\section{Bibliografía}

AHMED, S. The Cultural Politics of Emotion. Edimburgo: Edinburgh University Press, 2004.

BERSANI, L. Homos. Cambridge: Harvard University Press, 1995.

BERKINS, L. Para nosotras, tolerancia cero. Pagina12, 7 sep. 2012. Suplemento Soy. Disponible en: <https://www.pagina12.com.ar/diario/suplementos/soy/12609-2012-09-07.html. Acceso en: 12 ago. 2017.

BUTLER, J. El género en disputa: El feminismo y la subversión de la identidad. Barcelona: Paidós, 2007.

DAVIS, L. Enforcing Normalcy: Disability, Deafness, and the Body. Londres: Verso, 1995.

DUGGAN, L. The New Homonormativity: The Sexual Politics of Neoliberalism. In: CASTRONOVO, R.; NELSON, D. (eds.). Materializing Democracy. Towards a Revitalized Cultural Politics. Durham; Londres: Duke University Press, 2002. p. 175-194.

EDELMAN, L. No Future: Queer Theory and the Death Drive. Durham; Londres: Duke University Press, 2004.

FOUCAULT, M. Historia de la sexualidad I: la voluntad de saber. Buenos Aires: FCE, 2006.

GROSZ, E. Space, Time, and Perversion. In: GROSZ, E. Space, Time and Perversion: Essays on the Politics of Bodies. Nueva York; Londres: Routledge, 1995. p. 207-227. 
HALBERSTAM, J. Straight Eye For the Queer Theorist - A Review of "Queer Theory Without Antinormativity". Bully bloggers, 12 sep. 2015. Disponible en: $<$ https://bullybloggers.wordpress.com/2015/09/12/straight-eye-for-the-queer-theorist-a-review-of-queer-theory-without-antinormativity-by-jack-halberstam/>. Acceso en: 13 jul. 2017.

HALBERSTAM, J. Between Butches. En: MUNT, S. Butch/Femme: Inside Lesbian Gender. Londres; Washington: Cassell, 1998. p. 57-66.

HALPERIN, D. San Foucault: Para una hagiografía gay. Buenos Aires: El cuenco de Plata, 2007.

HOLLYWOOD, A. The Normal, the Queer, and the Middle Ages. Journal of the History of Sexuality, v.10, n. 2, p. 173-179, 2001.

PROSSER, J. Second Skins: the Body Narratives of Transsexuality. Nueva York: Columbia University Press, 1998.

TURNER, W. A Genealogy of Queer Theory. Filadelfia: Temple University Press, 2000. WARNER, M. The Trouble with Normal: Sex, Politics, and the Ethics of Queer Life. Nueva York: The Free Press, 1999.

WARNER, M. Queer and Then? The Chronicle of Higher Education, 1 ene. 2012. Disponible en: <http://chronicle.com/article/QueerThen-/130161/> Acceso en: 12 nov. 2018.

WIEGMAN, R.; WILSON, E. Introduction: Antinormativity's Queer Conventions. differences: A Journal of Feminist Cultural Studies, v. 26, n. 1, p. 1-25, 2015.

Recibido: 25/08/2017

Received: 08/25/2017

Aprobado: 21/06/2018 Approved: 06/21/2018 